\title{
Expression Profile of Epithelial Protein Lost in Neoplasm-Alpha (EPLIN- $\alpha$ ) in Human Pulmonary Cancer and Its Impact on SKMES-1 Cells in Vitro
}

\author{
Yinan Liu ${ }^{1,2,3}$, Andrew J. Sanders ${ }^{1,2}$, Lijian Zhang ${ }^{1,3^{*}}$, Wen G. Jiang ${ }^{12^{*}}$ \\ ${ }^{1}$ Cardiff University-Peking University School of Oncology Joint Institute, Cardiff, UK; ${ }^{2}$ Metastasis and Angiogenesis Research \\ Group, Cardiff University School of Medicine, Cardiff, UK; ${ }^{3}$ Key Laboratory of Carcinogenesis and Translational Research (Minis- \\ try of Education), Department of Thoracic Surgery II, Peking University Cancer Hospital and Institute, Beijing, China. \\ Email: *lijzhang@yeah.net, *jiangw@cf.ac.uk
}

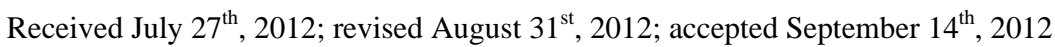

\begin{abstract}
Epithelial Protein Lost in Neoplasm (EPLIN) is a cytoskeletal associated protein implicated in regulating actin dynamoics and cellular motility and whose expression is frequently downregulated in a number of human cancers. The current study examined the expression levels of EPLIN- $\alpha$ in a pulmonary cancer cohort and its association with clinical pathological factors using quantitative polymerase chain reaction. Additionally, EPLIN- $\alpha$ was over-expressed in the SKMES1 pulmonary cancer cell line through transfection with a plasmid containing the expression sequence for EPLIN- $\alpha$. The role of EPLIN- $\alpha$ was subsequently examined using a variety of in vitro functional assays. Decreased levels of EPLIN- $\alpha$ were seen in cancerous tissues compared to normal background tissue. Lower levels of EPLIN- $\alpha$ were also associated with higher TNM stage and nodal involvement. In vitro over-expression of EPLIN- $\alpha$ inhibited SKMES-1 growth rates ( $p=0.05$ vs plasmid control) and motility ( $p=0.002$ vs plasmid control), though did not have any significant effects on cell-matrix adhesion or cell invasion. Taken together, the current study indicates that lower levels of EPLIN- $\alpha$ may be associated with poorer prognosis and more advanced pulmonary cancer, where this molecule appears to play a suppressive role on cell growth and migration.
\end{abstract}

Keywords: EPLIN- $\alpha$; Pulmonary Cancer; Cell Migration; ECIS

\section{Introduction}

Pulmonary cancer is one of the most fatal cancers, with distant metastasis being a key factor in the poor prognosis associated with this cancer. Epithelial protein lost in neoplasm (EPLIN) has previously been found to localise with actin stress fibres and play important roles in regulating actin dynamics and linking the catenin-cadherin complex to F-actin [1-3], suggesting a key role for this molecule in regulating cellular motility.

Since the discovery of EPLIN, as a molecule differenttially expressed between normal oral epithelial cells and HPV-immortalised oral epithelial cell lines, scientific interest has focused on the role of this molecule in cancer, with a number of studies reporting aberrant expression of EPLIN in cancerous cells and tissues of various cancer types including, breast, prostate and oesophageal cancers [4-8]. EPLIN, also known as Lima-1 (LIM domain and actin binding-1), contains a centrally located LIM domain and exists as two isoforms, known as EPLIN- $\alpha$ and

${ }^{*}$ Corresponding authors.
EPLIN- $\beta$, with the EPLIN- $\beta$ isoform containing an additional 160 amino acids at the N-terminus. The human gene for EPLIN consists of 11 exons, spanning more than $100 \mathrm{~kb}$, with different transcriptional starting points across this gene accounting for the EPLIN- $\alpha(90 \mathrm{kDa})$ and EPLIN- $\beta$ (110 kDa) isoforms [8,9]. Previous studies have suggested roles for EPLIN- $\alpha$ in cytokinesis, where loss of EPLIN- $\alpha$ in cancerous cells results in the mis-localisation of cytokinesis proteins resulting in enhanced genomic instability [10]. Numerous studies have also implicated the loss of EPLIN- $\alpha$ as contributing to the enhanced motility and invasiveness of cancer cells [1-3,5,6, 11,12]. EPLIN- $\alpha$ can bind actin monomers through the $\mathrm{NH}_{2}$ and $\mathrm{COOH}$ protein ends and can also bind F-actin, demonstrating a role in actin stabilisation [2]. Extracellular signal regulated kinase (ERK) phosphorylation of EPLIN has also been shown to reduce the C-terminal protein affinity for F-actin, suggesting that ERK phosphorylation may be key to EPLINs role in regulating actin dynamics [12]. EPLIN- $\alpha$ has also demonstrated the capacity to link the cadherin-catenin complex to F-actin 
through its ability to bind $\alpha$-catenin [3]. Thus, EPLIN- $\alpha$ appear to play key roles in regulating actin dynamics and motility in normal cells. The loss of this molecule in cancerous cells likely impacts on these key functions, leading to a more invasive phenotype. Clinical studies have further highlighted the importance of EPLIN- $\alpha$ in cancer progression with lower levels of this molecule being associated with poor prognosis predictive factors such as TNM stage, grade and patient survival rate in numerous cancers including breast, prostate and oesophageal cancers $[5,6,11]$. In support of clinical observations, additional work has demonstrated that the forced expression of EPLIN- $\alpha$ in prostate, breast and oesophageal cancer cells can impact on aggressive traits in vitro and in vivo [5-7]. Taken together all these studies indicate that EPLIN- $\alpha$ may act as a potential prognostic indicator and that the molecule may act as a protective factor in cancer progression.

Whilst the importance and role of EPLIN- $\alpha$ in a number of cancers is beginning to become apparent, its role in pulmonary cancer is currently unstudied. In the present study, the expression of EPLIN- $\alpha$ was examined in a cohort of pulmonary cancer samples and cell lines. Pulmonary cancer cells were forced to express this molecule, though transfection with a mammalian expression plasmid containing the full sequence of EPLIN- $\alpha$, in order to establish the functional role of EPLIN- $\alpha$ in pulmonary cancer cells in vitro.

\section{Materials and Methods}

\subsection{Cell Lines and Maintenance}

Human pulmonary cancer cell lines, SKMES-1 and A549 were purchased from ECACC (European Collection of Animal Cell Culture, Salisbury, England, UK) and maintained in Dubecco's Modified Eagle Medium (DMEM) (Sigma, Dorset, UK) supplemented with penicillin, streptomycin and $10 \%$ foetal calf serum (Sigma, Dorset, UK). The cells were incubated at $37^{\circ} \mathrm{C}, 5 \% \mathrm{CO}_{2}$ and $95 \%$ humidity.

\subsection{Pulmonary Tissue Sample Collection}

Paired normal and tumour pulmonary tissues $(\mathrm{n}=83$ pairs) were collected immediately after surgery and stored at $-80^{\circ} \mathrm{C}$ until use. Ethical approval and informed consents were obtained from the local ethics committee and patients respectively. The clinical follow-up was routinely performed following surgery and the median follow-up period was 120 months. Details of histology were obtained from pathology reports and confirmed by a consultant pathologist.

\subsection{Generation of SKMES-1 Cells Over-Expressing EPLIN- $\alpha$}

A plasmid containing the expression sequence for EPLIN- $\alpha$ has previously been generated and used within our laboratories [5-7,13]. In brief, the full length sequence for EPLIN- $\alpha$ was generated from mammary tissue cDNA using a combination of the following amplifycation primers, 5'ATGGAAAATTGTCTAGGAGA'3 (EPLINaExF1), 5'ATGGAAAATTGTCTAGGAGAA'3 (EPLINaExF2) and 5'TCACTCTTCATCCTCATCCTC'3 (EPLINaExR1), together with a high fidelity PCR mastermix (AbGene, Epsom, UK). The product size was verified before being T-A cloned into the pEF6/V5-His mammalian expression vector (Invitrogen, Paisley, UK). Plasmids were then inserted into chemically competent TOP10 bacteria, amplified and plated under ampicillin $(100 \mu \mathrm{g} / \mathrm{ml})$ selection. Colonies which grew were subjected to orientation analysis and bacteria containing plasmids with correctly orientated inserts were selected, amplified and harvested for plasmid extraction (GenElute, Sigma, Dorset, UK). This resource was used to transfect the human pulmonary SKMES-1 cancer cell line, which demonstrated minimal expression levels of EPLIN- $\alpha$. SKMES- 1 cells were transfected with either the EPLIN- $\alpha$ expression plasmid or a closed pEF6 plasmid and subjected to a period of selection ( $5 \mu \mathrm{g} / \mathrm{ml}$ blasticidin) before subsequent maintenance of the cells at $0.5 \mu \mathrm{g} / \mathrm{ml}$ blasticidin. Following the selective period, the expression of EPLIN- $\alpha$ was examined in the wild type and transfected cells, at the transcriptional level, using RT-PCR. Those cells containing the expression plasmid and displaying enhanced EPLIN- $\alpha$ expression were designated SKMES- $1^{\text {EPLIN- } \alpha \text { exp }}$, those containing the pEF6 control plasmid were designated SKMES-1 ${ }^{\mathrm{PEF} 6}$ and unaltered wild type cells were designated SKMES- $1^{\mathrm{WT}}$.

\subsection{RNA Extraction, Reverse Transcription-PCR, and Quantitative PCR}

RNA isolation was performed on either a $25 \mathrm{~cm}^{2}$ tissue culture flask or homogenised tissue samples using TRI Reagent (Sigma, Dorset, UK). RNA was subsequently quantified using a spectrophotometer (WPA UV 1101, Biotech Photometer, Cambridge, UK) before standardising all samples to a concentration of $500 \mathrm{ng}$ for use in reverse transcription (iScript ${ }^{\mathrm{TM}}$ Reverse Transcription Supermix kit, Bio-Rad Laboratories, Hemel Hempstead, UK). Routine RT-PCR was carried out using specific primers for EPLIN- $\alpha$ (Table 1). Amplification conditions were as follows: $94^{\circ} \mathrm{C}$ for 5 minutes, 32 cycles of $94^{\circ} \mathrm{C}$ for 40 seconds, $55^{\circ} \mathrm{C}$ for 40 seconds and $72^{\circ} \mathrm{C}$ for 60 seconds, followed by a final extension of $72^{\circ} \mathrm{C}$ for 10 minutes and $4^{\circ} \mathrm{C}$ hold. PCR products were separated on a 
Table. 1. Primer sequences used in PCR and Q-PCR.

\begin{tabular}{lll}
\hline Primer set & Sense & Anti-sense \\
\hline GAPDH probe & ATGATATCGCCGCGCTCA & CGCTCGGTGAGGATCTTCA \\
EPLIN probe/Q-PCR & AAGCAAAAATGAAAACGAAG & ACTGAACCTGACCGTACAGACACCCACCTTAGCAA \\
GAPDH Q-PCR & CTGAGTACGTCGTGGAGTC & ACTGAACCTGACCGTACACAGAGATGATGACCCTTTTG \\
\hline
\end{tabular}

Z-sequence on Q-PCR primers is 5' ACTGAACCTGACCGTACA 3'.

$2 \%$ agarose gel and documented, following ethidium bromide staining, using a digital camera mounted over a UV transluminator.

The level of EPLIN- $\alpha$ transcript present in the clinical samples was determined using real-time quantitative PCR, based on the Amplifluor technology and modified from a method reported previously [5]. Briefly, primers were designed in a similar way as to those used in conventional PCR. To one of the primer pairs, an additional sequence was added, known as the $\mathrm{Z}$ sequence, which is complementary to the universal $\mathrm{Z}$ probe (Intergen Inc., Oxford, England, UK). The reaction was carried out using the following: Hot-start Q-master mix (Abgene, Epsom, UK), 10 pmol of specific forward primer, 1 pmol reverse primer (containing the $Z$ sequence), $10 \mathrm{pmol}$ of FAM-tagged probe (Intergen), and cDNA from approximately 50 ng RNA. The reaction was carried out using an IcyclerIQ ${ }^{\mathrm{TM}}$ (Bio-Rad, surrey, UK). The following conditions were used in the reaction: $94^{\circ} \mathrm{C}$ for 12 minutes, 60 cycles of $94^{\circ} \mathrm{C}$ for 15 seconds, $55^{\circ} \mathrm{C}$ for 40 seconds and $72^{\circ} \mathrm{C}$ for 20 seconds. The levels of the EPLIN- $\alpha$ transcripts are presented as transcript copies per 50 ng RNA and values are calculated based on an internal standard that was simultaneously amplified during the same quantitative real-time PCR.

\subsection{In Vitro Cell Growth Assay}

Cells were seeded into triplicate 96-well plates at a seeding density of 3000 cells per well. The plates were incubated for differing periods (overnight, 3 and 5 days). Following incubation for the appropriate time, plates were fixed in $4 \%$ formalin $(\mathrm{v} / \mathrm{v})$ and stained with $0.5 \%$ $(\mathrm{w} / \mathrm{v})$ crystal violet. Crystal violet stain was extracted using $10 \%(\mathrm{v} / \mathrm{v})$ acetic acid and the absorbance was detected at a wavelength of $540 \mathrm{~nm}$ using a spectrophotometer.

\subsection{In Vitro Invasion Assay}

This was undertaken following a previously described method [5,6]. Transwell inserts with $8.0 \mu \mathrm{m}$ pores were coated with $50 \mu \mathrm{g}$ Matrigel (BD Bioscience, Oxford, UK) and air dried. The Matrigel was then rehydrated before seeding 30,000 cells to each insert. After 72 hours, any cells that had invaded to the underside of the insert were fixed in 4\% formalin and stained in crystal violet. Cell invasion was quantified by assessing the number of stained cells that had invaded to the underside of the insert in random microscopic fields.

\subsection{In Vitro Matrix Adhesion Assay}

Wells of a 96 well plate were pre-coated with $5 \mu \mathrm{g}$ of Matrigel and air dried. The Matrigel layer was then rehydrated before seeding 45,000 cells onto the matrix layer and incubating for 40 minutes. Following this incubation, non-adherent cells were removed through numerous washes with BSS before fixing adherent cells in formalin and staining with crystal violet. Cell-matrix adhesion was then quantified under the microscope by assessing the number of adherent cells in random microscopic fields.

\subsection{ECIS Based Cellular Motility Assays}

Cell motility was assessed using the Electric Cell-substrate Impedance Sensing (ECIS) system (Applied Biophysics Inc, NJ, US) and 96W1E arrays. One hundred and twenty thousand cells (SKMES-1 ${ }^{\mathrm{PEF} 6}$ or SKMES$1^{\text {EPLIN- } \alpha \text { exp }}$ ) were seeded into each well. These cells were allowed to settle and attach to the array wells to form a confluent monolayer. This monolayer was subsequently wounded, through the application of an electrical charge to the electrode. The change in resistance of the cell layer was recorded for a number of hours as the surrounding cells recovered and migrated onto the electrode to close the wound. Additional analysis was performed to assess the importance of PLC $\gamma$ signalling in EPLIN- $\alpha$ regulated migration using a PLC $\gamma$ inhibitor (CalBiochem, Nottingham, England, UK). To accomplish this, similar experiments were set up to examine the motility rates of SKMES- $1^{\text {pEF6 }}$ and SKMES- $1^{\text {EPLIN- } \alpha \text { exp }}$ cells, both in the presence and absence of 100nM PLC $\gamma$ inhibitor.

\subsection{Statistical Analysis}

The Minitab 14 statistical software package was used to carry out statistical analysis. Normally distributed data was analysed using two-sample, two-tailed t-tests and non-normally distributed data was analysed using the Mann-Whitney test. Two Way ANOVA analysis of mi- 
gration data was undertaken using the SIGMAPLOT 11 statistical package. Statistical comparisons were made between the SKMES- $1^{\mathrm{pEF} 6}$ and SKMES-1 ${ }^{\mathrm{EPLIN}-\alpha \text { exp }}$ cells.

\section{Results}

\subsection{The Expression of EPLIN- $\alpha$ in Pulmonary Cancer}

The expression of EPLIN- $\alpha$ was examined in pulmonary cancer cell lines and in a clinical cohort of pulmonary cancer and normal background samples. The transcript expression of EPLIN- $\alpha$ in the SKMES-1 and A549 pulmonary cancer cell lines was determined using RT-PCR (Figure 1(a)). Levels of EPLIN- $\alpha$ were found to be minimal in both of the cell lines tested. Quantitative PCR was also used to detect EPLIN- $\alpha$ transcript levels in the clinical pulmonary cohort. EPLIN- $\alpha$ expression was found to be significantly reduced in pulmonary tumour samples (139 \pm 49 copies/50ng RNA), compared to the normal background tissues (3373 \pm 1266 copies/50ng RNA, $\mathrm{p}=$ 0.013) (Figure 1(b)).

(a)
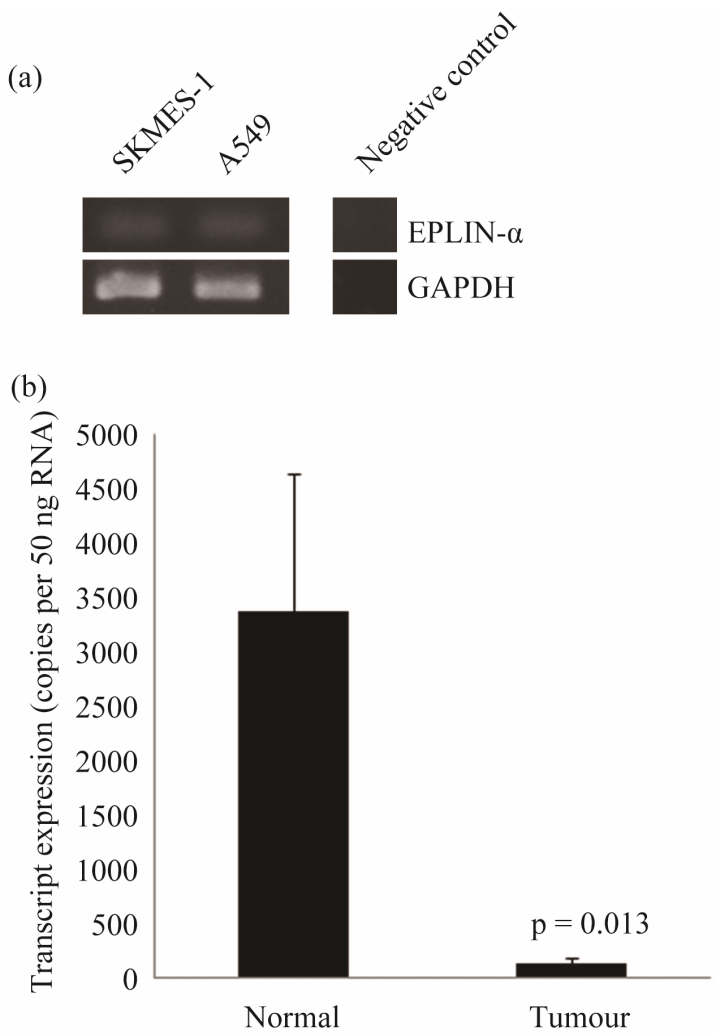

Figure 1. Expression of epithelial protein lost in neoplasm- $\alpha$ (EPLIN- $\alpha$ ) in pulmonary cancer cell lines and tissues. (a) EPLIN- $\alpha$ expression was found to be very weak in both SKMES-1 and A549 pulmonary cancer cell lines using RTPCR; (b) EPLIN- $\alpha$ transcript levels were also significantly decreased in tumour tissue compared to normal pulmonary tissues $(p=0.013)$.

\subsection{Association of EPLIN- $\alpha$ with Clinical Pathological Details}

To assess the importance of EPLIN- $\alpha$ expression in disease progression, EPLIN- $\alpha$ transcript levels in the pulmonary cancer samples were analysed against important clinical statuses, such as histological type, grade, node status, and TNM staging. Similar levels of EPLIN- $\alpha$ transcript was seen in squamous cancers $(175 \pm 70)$ and adenocarcinomas (159 \pm 100$)$. Reduced transcript levels of EPLIN- $\alpha$ were observed in small cell lung cancer (35 \pm 17 ), compared to squamous cancers, though this was not quite significant $(\mathrm{p}=0.06)$. Significant reductions in EPLIN- $\alpha$ transcript levels were seen in other pulmonary cancers (pulmonary cancers other than squamous, adenocarcinoma or small cell) compared to squamous cancer $(\mathrm{p}=0.019)$. As sample number was very small $(\mathrm{n}=3)$, the statistical comparisons of the other types such as carcinoid was not possible (Figure 2(a)). Expression of EPLIN- $\alpha$ was discovered to be elevated in tumour samples of a lower TNM1 stage (391 \pm 169$)$ compared to the more advanced TNM2 (74 $\pm 41, \mathrm{p}=0.08$ vs TNM1) and TNM3 ( $45 \pm 15, \mathrm{p}=0.05$, vs TNM1) tumours (Figure 2(b)). Higher levels of EPLIN- $\alpha$ transcript were detected in lymph node negative tumours (N0, $271 \pm 113$ ) than in those with local lymph node involvement (N1) (75 \pm 34 , $\mathrm{p}=0.1$, vs N0) and those with advanced lymph node metastasis (N2, $42 \pm 17, \mathrm{p}=0.05$, vs N0) (Figure 2(c)). It was also noted that samples from patients who had vessel cancerous embolus had a significantly lower expression level of EPLIN- $\alpha$ compared to embolus negative patients (21 \pm 18 vs $190 \pm 77$ respectively, $\mathrm{p}=0.037)$ (Figure 2(d)).

\subsection{Impact of EPLIN- $\alpha$ on in Vitro Growth, Invasion, and Cell-Matrix Adhesion}

To further evaluate the biological function of EPLIN- $\alpha$ in pulmonary cancer, SKMES-1 cells were transfected with a mammalian EPLIN- $\alpha$ expression plasmid. Enhanced EPLIN- $\alpha$ expression was confirmed in cells transfected with the expression plasmid (SKMES-1 $1^{\text {EPLIN- } \alpha \text { exp }}$ ) compared to wild type (SKMES- $1^{\mathrm{WT}}$ ) and empty plasmid transfected (SKMES-1 ${ }^{\mathrm{pEF}}$ ) cells using RT-PCR (Figure 3(a)). Over-expression of EPLIN- $\alpha$ resulted in a reduced rate of growth in vitro (Figure 3(b)), with significant reductions in growth rates seen between SKMES- $1^{\text {EPLIN- } \alpha \text { exp }}$ and SKMES- $1^{\mathrm{pEF} 6}$ over a 5 day incubation period $(\mathrm{p}=$ 0.05). In contrast to this, forced expression of EPLIN- $\alpha$ appeared to have little impact on cell-matrix adhesion and cellular invasion, with no significant differences in either of these traits being observed between SKMES- $1^{\mathrm{pEF} 6}$ control cells and SKMES- $1^{\text {EPLIN- } \alpha \text { exp }}$ cells ( $p>0.05$ in both cases) (Figures 3(c) and (d)). 
(a)

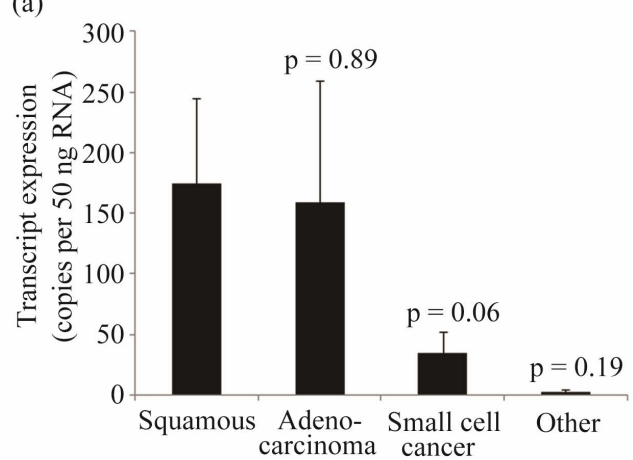

(c)

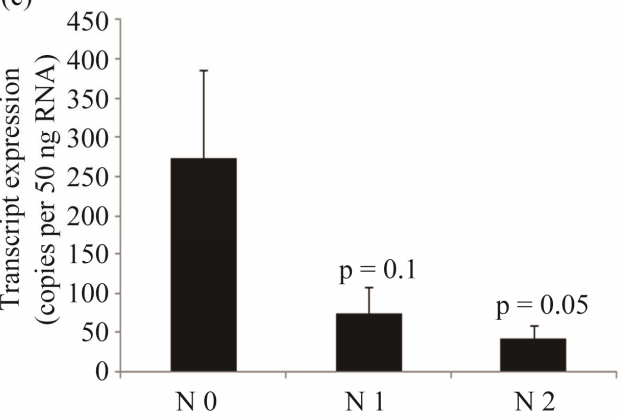

(b)

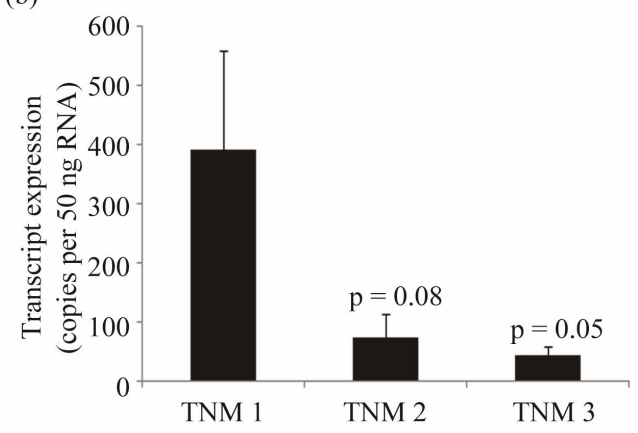

(d)

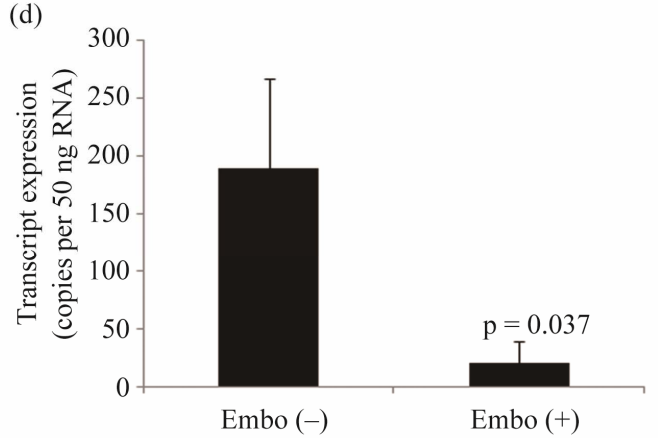

Figure 2. Association of EPLN- $\alpha$ with histological type, nodal status, and TNM stage. (a) EPLIN- $\alpha$ transcript levels were found to be highest in the squamous and adenocarcinoma cancers, reduced levels of EPLIN- $\alpha$ were observed in the small cell cancers $(p=0.06$ vs squamous) and combined other types of pulmonary cancer $(p=0.019)$; (b) Decreased levels of EPLIN- $\alpha$ were also associated with a more advanced TNM stage. Substantial decreases in EPLIN- $\alpha$ expression were observed between TNM1 and TNM2 $(p=0.08)$ and TNM1 and TNM3 $(p=0.05)$; (c) Similarly, decreased expression of EPLIN- $\alpha$ was also associated with lymph node involvement, with highest levels of EPLIN- $\alpha$ being observed in patients with no lymph node involvement (N0). Decreased levels were seen in those patients with local lymph node involvement (N1; $p=0.1$ vs N0), with lowest levels observed in patients who had advanced lymph node involvement (N2; $p=0.05$ vs N0); (d) Significantly reduced EPLIN- $\alpha$ expression was also apparent in patients with local advanced cancers with vessel embolus $(\mathbf{p}=0.037)$.

\subsection{EPLIN- $\alpha$ Over-Expression Inhibits Pulmonary Cell Migration Rates}

An Electric Cell Impedance Sensing (ECIS) method was used to investigate the impact of EPLIN- $\alpha$ over-expression on cell motility (Figure 4). Forced expression of EPLIN- $\alpha$ in SKMES-1 pulmonary cancer cells dramatically inhibited monolayer recovery following electrical wounding. Significant differences in recovery (assessed through change in resistance over the electrode as cells migrated to re-cover the electrode) over the 6 hour period were seen between SKMES-1 ${ }^{\mathrm{pEF} 6}$ control and SKMES-1 ${ }^{\text {EPLIN- } \alpha \text { exp }}$ cells $(p=0.002)$ (Figure 4(a)). Treatment with the PLC $\gamma$ inhibitor seemed to have little effect on the recovery rates of either SKMES- $1^{\mathrm{pEF} 6}$ control cells or SKMES-1 ${ }^{\text {EPLIN- } \alpha \text { exp }}$ cells (Figure 4(b)). In both cases, treatment with PLC $\gamma$ inhibitor did not significantly impact on the migratory rate of either cell line compared to the untreated equivalent $(\mathrm{p}>0.05)$.

\section{Discussion}

Epithelial protein lost in neoplasm is a cytoskeletal asso- ciated protein involved in the regulation of actin dynamics and subsequently in cell motility [2,3]. The expression of EPLIN- $\alpha$ has been found to be down-regulated in a number of oral, breast, oesophageal and prostate cancer cell lines compared to their normal counterparts [5-8]. Previous studies from our laboratories have provided data supporting a tumour/metastasis suppressive role for EPLIN- $\alpha$, where enhanced levels of EPLIN- $\alpha$ can negatively impact on key metastatic and angiogenic traits in vitro and in vivo $[5,6,13]$. This is supported by data from our clinical cohorts indicating that reduced EPLIN- $\alpha$ levels are associated with poor NPI prognosis and lower patient survival rates in breast cancer patients [5].

The clinical data obtained in the current study, appears to be in line with previous observations. Transcript levels of EPLIN- $\alpha$ where found to be significantly reduced in tumour tissues compared to normal tissues. We further analyzed the quantity of EPLIN- $\alpha$ transcript in pulmonary cancer samples against the corresponding clinical data. Relatively high levels of EPLIN- $\alpha$ transcript were detected in squamous pulmonary cancer and adenocarcinomas compared to small cell cancers and other types of 
(a)

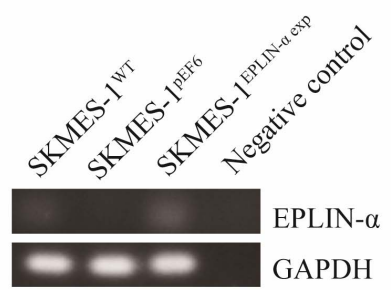

(c)

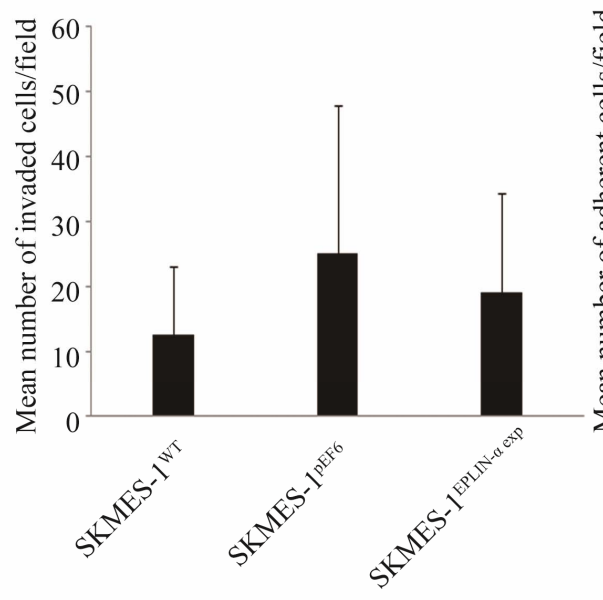

(b)

(d)
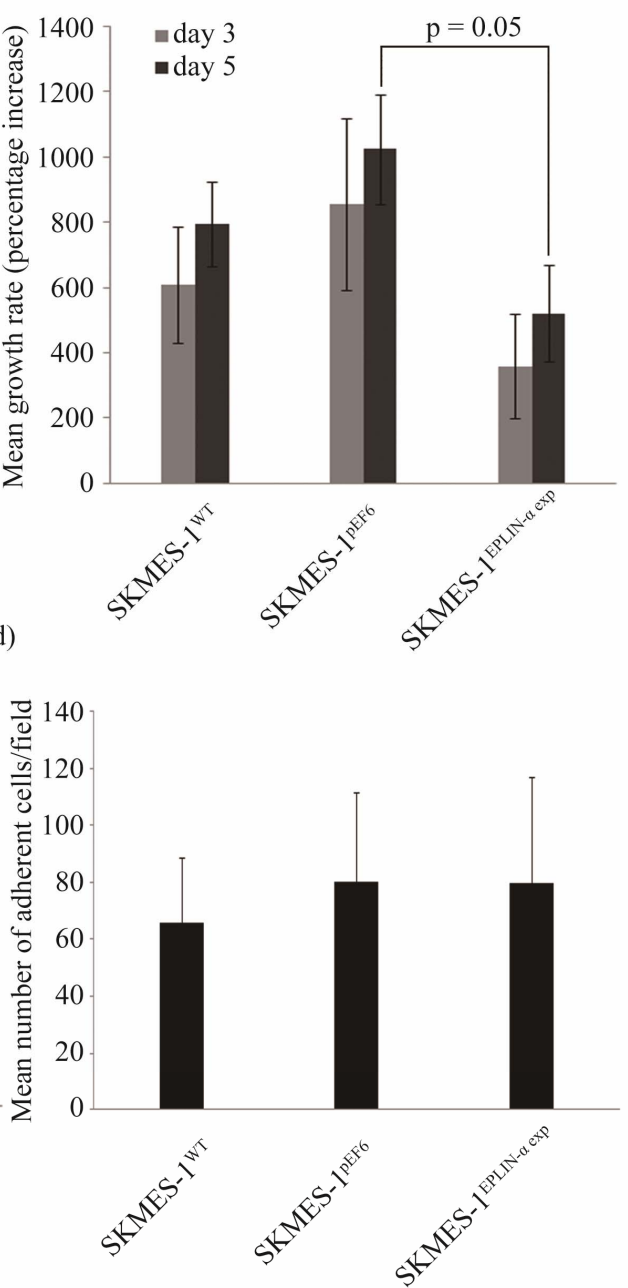

Figure 3. Impact of EPLIN- $\alpha$ over-expression on SKMES-1 pulmonary cancer cells. (a) Successful over-expression of EPLIN$\alpha$ in SKMES-1 cells was seen in cells containing the expression plasmid (SKMES-1 ${ }^{\text {EPLIN- } \alpha \text { exp }}$ ) compared to wild type $\left(\right.$ SKMES-1 ${ }^{\text {WT }}$ ) and plasmid control (SKMES-1 ${ }^{\text {pEF6 }}$ ) cells using RT-PCR; (b) Over-expression of EPLIN- $\alpha$ resulted in a decreased rate of growth, in comparison to the plasmid control line, over a 5 day incubation period $(p=0.05)$. No significant effect on SKMES-1 invasiveness; (c) Or cell matrix-adhesion; (d) was observed following over-expression of EPLIN- $\alpha$ (p > 0.05). Mean values $+/-$ SEM are shown.
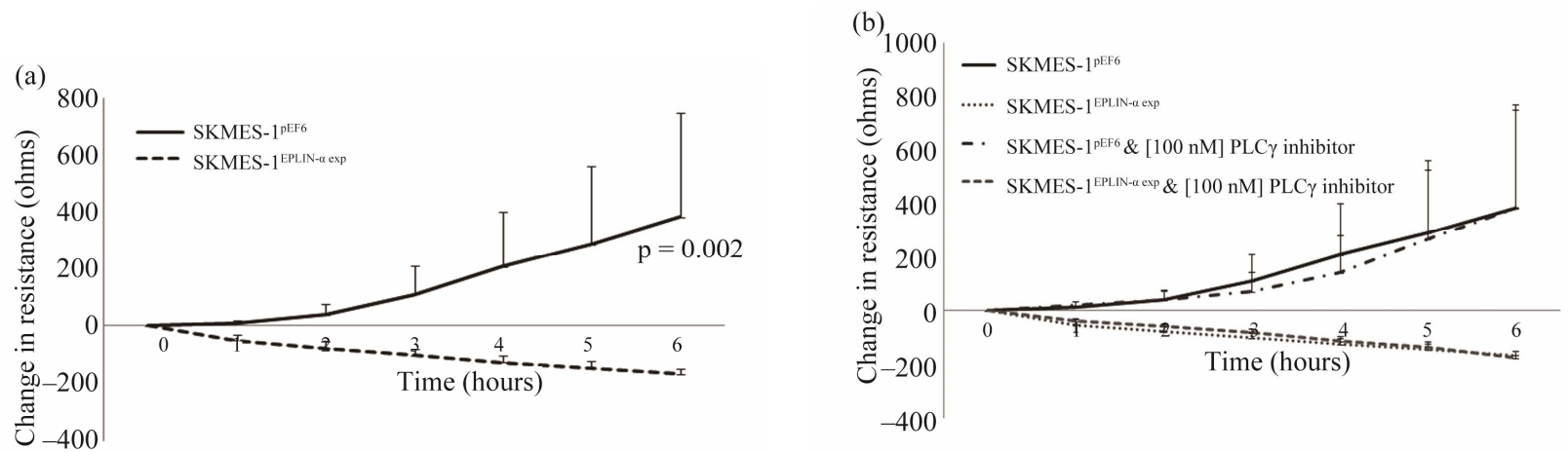

Figure 4. Impact of EPLIN- $\alpha$ over-expression on SKMES-1 cell motility. (a) Over-expression of EPLIN- $\alpha$ significantly inhibited cell motility in SKMES-1 cells, with significant differences being seen between SKMES-1 ${ }^{\text {pEF6 }}$ and SKMES-1 ${ }^{\text {EPLIN- } \alpha \text { exp }}$ cells over time $(p=0.002)$; (b) Inhibition of PLC $\gamma$ signalling by treatment of cells with a PLC $\gamma$ inhibitor did not have any significant effects on the motility rate of either cell line (vs untreated control, $p>0.05$ ). Representative data is shown. 
pulmonary cancers, such as carcinoid. Expression levels of EPLIN- $\alpha$ appeared to associate with the TNM stage of the cancer, with highest levels being seen in the lower TNM1 stage and levels reducing at TNM2 and TNM3 stages with close to significant and significant differences observed between TNM1 vs TNM2 and TNM1 vs TNM3 respectively. This observation is in line with observations from the clinical breast cohort [5], where lower level of EPLIN- $\alpha$ were seen in the higher TNM stages and similarly indicates that a loss of EPLIN- $\alpha$ expression occurs during the advancement of pulmonary cancer. Decreased expression levels of EPLIN- $\alpha$ were also found to associate with lymphatic involvement. Highest levels of EPLIN- $\alpha$ transcripts were observed in cancers with no lymphatic involvement (N0) and large reductions in EPLIN- $\alpha$ expression, in comparison to no lymphatic involvement, were seen in tissues where local lymph node involvement was apparent (N1), with further reductions in EPLIN- $\alpha$ expression being apparent in the tissues from patients with advanced lymph node involvement (N2). A recent study has also highlighted reduced expression of EPLIN in lymph node metastasis in a number of epithelial cancers, including prostate, colorectal, breast and squamous cell carcinoma of the head and neck [11]. The data presented here further suggests that EPLIN- $\alpha$ may be a key contributing factor in determining the likelihood of cancer cells metastasising through the lymphatic route in a variety of human cancers. Finally, our clinical data indicated that reduced EPLIN- $\alpha$ levels were associated with patients who had local advanced cancers with vessel cancerous embolus. Thus, the clinical results indicate that, similar to other studies on different cancer types, lower levels of EPLIN$\alpha$ are associated with a more aggressive pulmonary cancer and an increased likelihood of metastatic spread.

To support our clinical findings, we generated a SKMES-1 human lung cancer line over-expressing EPLIN- $\alpha$ and examined the impact of this over-expression on the cellular functions of this cell line. Forced expression of EPLIN- $\alpha$ brought about a reduction in SKMES-1 cell growth and motility compared to control cells. However, over-expression of EPLIN- $\alpha$ in this cell line did not seem to influence SKMES-1 invasiveness. This data is somewhat in line with the established role of EPLIN in motility. Previous studies from our laboratory have also found the over-expression of EPLIN- $\alpha$ to negatively impact on the cellular invasiveness and motility of MDAMB-231 breast cancer cells [5] and negatively affect the motility of HECV endothelial cells [13], though in oesophageal cancer cells over-expression of EPLIN- $\alpha$ had a greater influence on cellular invasiveness than motility [7]. Additionally, treatment with a PLC $\gamma$ inhibitor seemed to have similar effects on both control and EPLIN- $\alpha$ over-expressing cells, suggesting that the role that EPLIN- $\alpha$ plays in cellular motility in this cell line may not be linked to the PLC $\gamma$ signalling pathway. Thus, our data suggests that, in this lung cancer cell line, EPLIN- $\alpha$ may not play as great a role in cell invasion. The exact reason behind this observation, which is in contrast to other studies, is currently unknown. Further work to clarify this observation is required, examining the role of EPLIN- $\alpha$ in other pulmonary cancer cell lines using both over-expression and knockdown studies where possible.

Collectively, the present study suggests that EPLIN- $\alpha$ is inversely associated with the aggressiveness and clinical outcome of human pulmonary cancers and can influence in vitro cell growth and migration of lung cancer cells. Further data examining EPLIN- $\alpha$ expression in larger cohorts and also using in vivo metastasis models are required to fully explore the potential importance of EPLIN- $\alpha$ in pulmonary cancer.

\section{Acknowledgements}

Dr Yinan Liu is a recipient of the Albert Hung China Medical Scholarship of Cardiff University. The authors wish to thank Cancer Research Wales for their kind support of this work.

\section{REFERENCES}

[1] Y. Song, R. E. Maul, C. S. Gerbin and D. D. Chang, “Inhibition of Anchorage-Independent Growth of Transformed NIH3T3 Cells by Epithelial Protein Lost in Neoplasm (EPLIN) Requireslocalization of EPLIN to Actin Cytoskeleton," Molecular Biology of the Cell, Vol. 13, No. 4, 2002, pp. 1408-1416. doi:10.1091/mbc.01-08-0414

[2] R. S. Maul, Y. Song, K. J. Amann, S. C. Gerbin, T. D. Pollard and D. D. Chang, "EPLIN Regulates Actin Dynamics by Cross-Linking and Stabilizing Filaments," The Journal of Cell Biology, Vol. 160, No. 3, 2003, pp. 399407. doi:10.1083/jcb.200212057

[3] K. Abe and M. Takeichi, "EPLIN Mediates Linkage of the Cadherin-Catenin Complex to F-Actin and Stabilizes the Circumferential Actin Belt," Proceedings of the National Academy of Sciences, Vol. 105, No. 1, 2008, pp.1319. doi:10.1073/pnas.0710504105

[4] D. D. Chang, N.-H. Park, C. T. Denny, S. F. Nelson and M. Pe, "Characterization of Transformation Related Genes in Oral Cancer Cells,” Oncogene, Vol. 16, No. 15, 1998, pp. 1921-1930. doi:10.1038/sj.onc.1201715

[5] W. G. Jiang, T. A Martin, J. M. Lewis-Russell, A. Douglas-Jones, L. Ye and R. E. Mansel, "Eplin-Alpha Expression in Human Breast Cancer, the Impact on Cellular Migration and Clinical Outcome,” Molecular Cancer, Vol. 7, 2008, pp. 71-80. doi:10.1186/1476-4598-7-71

[6] A. J. Sanders, T. A. Martin, L. Ye, M. D. Mason and W. G. Jiang, "EPLIN Is a Negative Regulator of Prostate Cancer Growth and Invasion,” Journal of Urology, Vol. 
186, No. 1, 2011, pp. 295-301. doi:10.1016/j.juro.2011.03.038

[7] Y. Liu, A. J. Sanders, L. Zhang and W. G. Jiang, "EPLIN-Alpha Expression in Human Oesophageal Cancer and Its Impact on Cellular Aggressiveness and Clinical Outcome,” Anticancer Research, Vol. 32, No. 4, 2012, pp. 1283-1289.

[8] R. S. Maul and D. D. Chang, "EPLIN, Epithelial Protein Lost in Neoplasm,” Oncogene, Vol. 18, No. 54, 1999, pp. 7838-7841. doi:10.1038/sj.onc.1203206

[9] S. Chen, R. S. Maul, H. R. Kim and D. D. Chang, “Characterization of the Human EPLIN (Epithelial Protein Lost in Neoplasm) Gene Reveals Distinct Promoters for the Two EPLIN Isoforms,” Gene, Vol. 248, No. 1-2, 2000, pp. 69-76. doi:10.1016/S0378-1119(00)00144-X

[10] M. Chircop, V. Oakes, M. E. Graham, M. P. Ma, C. M. Smith, P. J. Robinson and K. K Khanna, "The ActinBinding and Bundling Protein, EPLIN, Is Required for Cytokinesis,” Cell Cycle, Vol. 8, No. 5, 2009, pp. 757764. doi: $10.4161 /$ cc.8.5.7878
[11] S. Zhang, X. Wang, A. O. Osunkoya, S. Iqbal, Y. Wang, Z. Chen, S. Muller, S. Josson, I. M. Coleman, P. S. Nelson, Y. A. Wang, R. Wang, D. M. Shin, F. F. Marshall, O. Kucuk, W. L.Chung, H. E. Zhau and D. Wu, "EPLIN Downregulation Promotes Epithelial-Mesenchymal Transition in Prostate Cancer Cells and Correlates with Clinical Lymph Node Metastasis,” Oncogene, Vol. 30, No. 50, 2011, pp. 4941-4952. doi:10.1038/onc.2011.199

[12] M. Y. Han, H. Kosako, T. Watanabe and S. Hattori, "Extracellular Signal-Regulated Kinase/Mitogen-Activated Protein Kinase Regulates Actin Organization and Cell Motility by Phosphorylating the Actin Cross-Linking Protein EPLIN,” Molecular and Cellular Biology, Vol. 27, No. 23, 2007, pp. 8190-8204. doi:10.1128/MCB.00661-07

[13] A. J. Sanders, L. Ye, M. D. Mason and W. G. Jiang, “The Impact of EPLIN $\alpha$ (Epithelial Protein Lost in Neoplasm) on Endothelial Cells, Angiogenesis and Tumorigenesis," Angiogenesis, Vol. 13, No. 4, 2010, pp. 317-326. doi:10.1007/s10456-010-9188-7 